\title{
Evolução da maturação e características fisico-químicas de uvas da cultivar Isabel sobre diferentes porta-enxertos na Região Norte do Paraná
}

\section{Ripening evolution and physico-chemical characteristics of 'Isabel' grape on differents rootstocks in North of Paraná.}

\author{
Alessandro Jefferson Sato ${ }^{1}$; Bruno Jubileu da Silva ${ }^{2}$; \\ Roseineide Bertolucci'; Mariana Carielo'; Marília Cherobin Guiraud ${ }^{3}$; \\ Inês Cristina de Batista Fonseca ${ }^{4}$; Sérgio Ruffo Roberto ${ }^{4 *}$
}

\section{Resumo}

O trabalho teve como objetivo avaliar a evolução da maturação e as características físico-químicas e produtivas da videira 'Isabel' (Vitis labrusca) sobre os porta-enxertos IAC 766 Campinas, IAC 572 Jales e 420-A no Norte do Paraná. O experimento foi conduzido em um pomar experimental pertencente ao Centro Tecnológico da Cooperativa Corol, localizado no município de Rolândia, PR. O plantio dos porta-enxertos foi realizado em julho de 2002, e a enxertia das copas em julho de 2003. O delineamento experimental adotado foi o inteiramente casualizado com 4 repetições. As plantas foram conduzidas no sistema GDC (Geneva Double Curtain) no espaçamento de 2,0 $\mathrm{m}$ entre plantas e 3,5 $\mathrm{m}$ entre linhas. A partir do início da maturação até 7 dias após a colheita foi feita coleta semanal de amostras de 60 bagas de cada tratamento para acompanhamento da evolução da maturação, e no momento da colheita avaliouse o teor de sólidos solúveis totais (SST), acidez titulável (AT), índice de maturação (SST/AT) e pH do mosto das bagas, além da massa e comprimento dos cachos, a massa e diâmetro das bagas e o número de cachos por planta e por ha. Foram também estimadas a produção $(\mathrm{kg} / \mathrm{planta})$ e produtividade $(\mathrm{t} / \mathrm{ha})$ das combinações copa/porta-enxerto. Os porta-enxertos exerceram influência semelhante sobre a evolução da maturação e as curvas melhor se ajustaram às equações de segundo e terceiro grau, no entanto para massa e comprimento dos cachos o 'IAC 766 Campinas' e o 'IAC 572 Jales' não diferiram entre si e foram superiores em relação ao '420-A'. Para massa e diâmetro das bagas não houve influência dos porta-enxertos e para o número de cachos por planta, produção e produtividade o 'IAC 766 Campinas foi superior em relação aos demais porta-enxertos. Para as características químicas no momento da colheita houve influência do porta-enxerto somente para o teor de SST, sendo o '420-A' inferior em relação aos demais.

Palavras-chave: Viticultura, suco, Vitis labrusca

\footnotetext{
Abstract

The aim of this research was to characterize the ripening evolution, physico-chemical and productive characteristcs of 'Isabel' (Vitis labrusca) grafted on 'IAC 766 Campinas', 'IAC 572 Jales' and '420-A' rootstocks for grape juice in the North of Paraná. The trial was carried out in a experimental vineyard located at Technology Center of Corol Cooperative, located at Rolândia, PR. The vineyard was

Aluno regular do curso de pós-graduação em Agronomia da Universidade Estadual de Londrina. Telefone: (43) 33417108.

2 Aluno regular do curso de pós-graduação em Agronomia da Universidade Estadual de Londrina.

3 Acadêmico do curso de graduação em Agronomia da Universidade Estadual de Londrina.

4 Prof. Adjunto do curso de Agronomia da Universidade Estadual de Londrina.

* Autor para correspondência
} 
established in July, 2002 and grafted in 2003. The randon design was used as the statistical model with four repetitions. The trees were cultivated in GDC (Geneva Double Curtain) system, in a $2.0 \times 3.5$ $\mathrm{m}$ spacing. From the ripening early ripening up to seven days after harvest were collected weekly 60 samples to evaluate the ripening evolution and at moment of the harvest were evaluated the text of total soluble solids (TSS), tritable acidity (TA), TSS/TA ratio and $\mathrm{pH}$, beyond the mass and length of the clusters, the mass and the diameter of the berries and the number of cluster per tree and per ha. It was also estimated the production ( $\mathrm{kg} / \mathrm{plant})$ and productivity of cultivars ( $\mathrm{t} / \mathrm{ha})$. The rootstocks had similar influence in the ripening evolution and it was better fitted to the square and cubic regressions however the mass and length of the clusters the 'IAC 766 Campinas' and 'IAC 572 Jales' had not difference between itself and they had been superior in relation to '420-A'. For mass and diameter of berries the rootstocks didn't have influence and for number of clusters per tree, production and productivity the 'IAC 766 Campianas' were superior in relation to others rootstocks.

Key words: Viticulture, juice, Vitis labrusca

\section{Introdução}

A viticultura é atualmente uma atividade promissora, devido principalmente ao crescente aumento no consumo de sucos de uva e vinhos, além do consumo "in natura". A cultura ocupa cerca de 74 mil ha em todo o território brasileiro, com produção de mais de 1 milhão de toneladas (MELLO, 2006).

No Paraná, a viticultura está em plena expansão principalmente na região Norte do Estado, sendo a maior parte da produção de uvas finas de mesa (KISHINO; GENTA; ROBERTO, 2007), além disso esta região possui uma particularidade, a dupla safra anual, que somente é possível devido ao clima local e ao uso da cianamida hidrogenada (KISHINO; GENTA; ROBERTO, 2007). No entanto, em alguns anos ocorre um excesso de produção de uvas de mesa, o que provoca queda no valor do produto, portanto torna-se necessário diversificar a produção, e o cultivo de uvas destinadas à produção de sucos $\mathrm{e}$ vinhos torna-se uma alternativa.

A produção de sucos de uvas no Brasil está em amplo crescimento, sendo que a sua comercialização em 2005 foi cerca de $25 \%$ maior do que em 2004. O consumo "per capita" ainda é baixo quando comparado a países europeus, porém cresceu muito nos últimos anos. Em 1995 o consumo "per capita" era de 0,15 litro e em 2005 este consumo atingiu 0,53 litro (MELLO, 2006).

O suco de uva brasileiro é elaborado com uvas americanas (RIZZON; MANFROI; MENEGUZZO,
1998), e uma das principais variedades utilizadas é a Isabel (Vitis labrusca) (CAMARGO, 2005). Esta variedade se adaptou muito bem à região sul do Brasil, e ocupa atualmente $30 \%$ da área de uvas do território nacional, além disso, é uma cultivar que se destaca pela sua alta produtividade e pelo grande potencial de acúmulo de açúcar.

Uma prática bastante utilizada na produção de uvas é o uso de porta-enxertos, entre eles se destacam o 'IAC 766 Campinas' (Riparia do Traviú x Vitis caribaea) e o 'IAC 572 Jales' (V. caribaea $\mathrm{x}$ Vitis riparia $\mathrm{x}$ Vitis rupestris 101-14) que são conhecidos por imprimir uma maior produtividade às variedades copa neles enxertados (POMMER; MAIA, 2003). Além destes existe também o ' $420-A$ ' (Vitis berlandieri $\mathrm{x}$ V. riparia) que é um porta-enxerto conhecido por limitar a produção e retardar o ciclo das variedades-copa, sendo interessante quando se deseja uma produção controlada (CAMARGO, 2003).

A qualidade do suco de uvas está diretamente relacionadaà qualidade das bagas utilizadas para asua elaboração, portanto quando se deseja cultivar uvas para processamento em regiões onde o seu cultivo é pouco conhecido é necessário que se realizem alguns estudos para conhecer o comportamento produtivo das variedades escolhidas, além do seu comportamento sobre os porta-enxertos utilizados na região. Portanto, o objetivo deste trabalho foi de avaliar o comportamento de maturação e produtivo da videira 'Isabel' sobre diferentes porta-enxertos na região Norte do Paraná. 


\section{Material e Métodos}

O experimento foi conduzido em um pomar experimental pertencente ao Centro Tecnológico da Cooperativa Corol, localizado no município de Rolândia, PR, cujas coordenadas geográficas são $23^{\circ}$ $27^{\prime}$ S, $51^{\circ} 47^{\prime} \mathrm{W}$, com $600 \mathrm{~m}$ de altitude, precipitação média anual de $1.610 \mathrm{~mm}$ e temperatura média anual de $21,2^{\circ} \mathrm{C}$. Estudou-se o comportamento da maturação e produtivo da videira 'Isabel' (Vitis labrusca), enxertada sobre os portas-enxertos IAC 766 Campinas (Riparia do Traviúx Vitis caribaea), IAC 572 Jales ( $V$. caribaea $x$ Vitis riparia $x$ Vitis rupestris 101-14) e 420-A (Vitis berlandieri $x V$. riparia).

$\mathrm{O}$ delineamento experimental adotado foi $\mathrm{o}$ inteiramente casualizado com 4 repetições, sendo cada parcela constituída por 4 plantas.

O material vegetal livre de vírus, tanto da variedade copa como porta-enxerto, foi obtido junto ao Banco de Germoplasma do Centro Nacional de Pesquisa em Uva e Vinho da Embrapa, localizado em Bento Gonçalves, RS. O plantio dos porta-enxertos foi realizado em julho de 2002, e a enxertia da copa em julho de 2003. As plantas foram conduzidas no sistema GDC (Geneva Double Curtain) no espaçamento de $2,0 \mathrm{~m}$ entre plantas e $3,5 \mathrm{~m}$ entre linhas, e em 2004 foi concluída a formação das videiras.

A poda de frutificação foi realizada no dia 03 de setembro de 2006, logo após o fim do período hibernal, quando se deu início o inchamento das gemas, deixando-se 2 gemas por esporão, e em seguida, foi aplicado o regulador de crescimento cianamida hidrogenada $(2,5 \%)$ para a quebra de dormência das gemas, com objetivo de se obter brotação uniforme das mesmas.

As características químicas das uvas das diferentes combinações copa/porta-enxerto, como teor de sólidos solúveis totais (SST), acidez titulável (AT), índice de maturação (SST/AT) e pH foram avaliadas a partir do início da maturação até 7 dias após a colheita, por meio de coletas semanais de 60 bagas de cada parcela, subdivididas em 4 sub-amostras. As análises foram realizadas no Laboratório de Análise de Frutas pertencente ao Centro de Ciências Agrárias da Universidade Estadual de Londrina, PR.

O teor de SST do mosto das uvas foi determinado em refratômetro digital de bancada com compensação automática de temperatura (Modelo DR 301-95, Krüss Optronic, Alemanha) por meio de esmagamento e posterior filtragem das amostras em algodão, e o resultado expresso em ${ }^{\circ}$ Brix.

As determinações do $\mathrm{pH}$ e da AT do suco foram realizadas em titulador potenciométrico digital (Modelo Tritoline Easy, Schott Geräte, Alemanha). $\mathrm{O}$ teor de AT foi obtido por titulação do suco com solução padronizada de $\mathrm{NaOH} 0,1 \mathrm{~N}$, adotandose como ponto final da titulação o $\mathrm{pH}=8,2$, e o resultado expresso em porcentagem de ácido tartárico (INSTITUTO ADOLFO LUTZ, 1985).

Por ocasião da colheita, foram registrados o número médio de cachos de cada parcela, com objetivo de se obter o número médio de cachos de cada combinação.

Para a determinação das características físicas da produção, foram coletados 4 cachos por parcela, onde se avaliou a massa $(\mathrm{g})$ e comprimento $(\mathrm{cm})$ dos cachos, e a massa (g) e o diâmetro das bagas (mm).

A massa dos cachos e das bagas foram determinadas utilizando-se balança digital, e o comprimento dos cachos e diâmetro das bagas foram obtidos por medições com régua graduada e paquímetro digital (modelo 727-6/150 - Starrett, Alemanha), respectivamente. Com os dados obtidos foram estimadas a produção por planta $(\mathrm{kg} /$ planta $)$ e a produtividade ( $\mathrm{t} / \mathrm{ha})$ de cada combinação copa/ porta-enxerto.

A comparação das médias dos tratamentos de todas as variáveis estudadas foi realizada por meio de análise de variância complementada por Tukey a $5 \%$. 


\section{Resultados e Discussão}

A evolução do teor de SST e de AT do mosto da uva 'Isabel' sobre os diferentes porta-enxertos estão representadas na Figura 1. Verifica-se que para o teor de SST não houve diferença significativa entre os porta-enxertos, pois a partir do início da maturação, ocorrida 94 dias após a poda, seguiu a tendência de crescimento progressivo até a colheita e posteriormente houve queda no valor de SST, sendo que para todos os tratamentos a curva de evolução melhor ajustou à regressão de terceiro grau ('IAC 766 Campinas': R2=97,3; 'IAC 572 Jales': $\mathrm{R}^{2}=98,0$; e '420-A': $\mathrm{R}^{2}=98,1$ ).

Este comportamento observado está relacionado às características fisiológicas de desenvolvimento da baga, pois no início do ciclo a maior parte do açúcar produzido é direcionada para as folhas, desenvolvimento da planta e do fruto, sobretudo para o crescimento e maturação da semente (BLOUIN; GUIMBERTEAU, 2004). Somente a partir da fase de início da maturação, é que ocorre uma modificação metabólica na translocação do açúcar, ocasionando desta forma, um grande acúmulo deste componente nas bagas, fase esta conhecida como "véraison".

Próximo à colheita, as bagas continuam acumulando açúcar, porém mais lentamente, e dependendo das condições climáticas, o teor de açúcar pode diminuir, pois este tende a se direcionar para outras partes das plantas onde será armazenado, como por exemplo, os tecidos lenhosos (BLOUIN; GUIMBERTEAU, 2004).

Observa-se também que a evolução do teor de AT do mosto de todas as combinações copa/portaenxerto é inverso à evolução do teor de SST, pois inicialmente este teor é alto e com a evolução da maturação há uma acentuada redução, atingindo valores mínimos no período próximo à colheita.
Para a AT, não houve influência significativa dos porta-enxertos sobre a copa, sendo que todos os tratamentos melhor se ajustaram à regressão de segundo grau ('IAC 766 Campinas': $\mathrm{R}^{2}=97,6$; 'IAC 572 Jales': $\mathrm{R}^{2}=97,9$; e '420-A': $\mathrm{R}^{2}=98,4$ ).

A evolução da acidez titulável está relacionada ao fato dos principais ácidos das videiras (tartárico e málico) serem sintetizados pelas folhas e pelas bagas ainda verdes, por isso, no início da maturação as bagas apresentam elevado teor de AT, e com a evolução da maturação, a demanda por energia aumenta e para suprir essa necessidade muitas vezes os ácidos são utilizados como fonte de energia na respiração celular (BLOUIN; GUIMBERTEAU, 2004). Além disso, fatores como a diluição dos ácidos orgânicos devido ao aumento do tamanho da baga, a migração de bases e conseqüente salificação dos ácidos orgânicos também contribuem para a redução no teor de AT (RIZZON; MIELE; MENEGUZZO, 2000).

Além do teor de SST e AT, existem outras características químicas importantes como índice de maturação (SST/AT) e pH que devem ser observadas na evolução da maturação, pois estão diretamente relacionadas com a qualidade da uvas.

O índice de maturação (SST/AT) pode ser uma boa opção para se determinar o ponto ideal de colheita das uvas, representa o equilíbrio entre o teor de açúcar e a acidez. Na Figura 2, observa-se que a evolução do teor de SST/AT seguiu a tendência de crescimento progressivo e melhor se ajustou à equação de regressão polinomial de terceiro grau quando para todos os porta-enxertos ('IAC 766 Campinas': $\mathrm{R}^{2}=96,8$; 'IAC 572 Jales': $\mathrm{R}^{2}=96,9$; e ' $\left.420-\mathrm{A}^{\prime}: \mathrm{R}^{2}=95,7\right)$. 

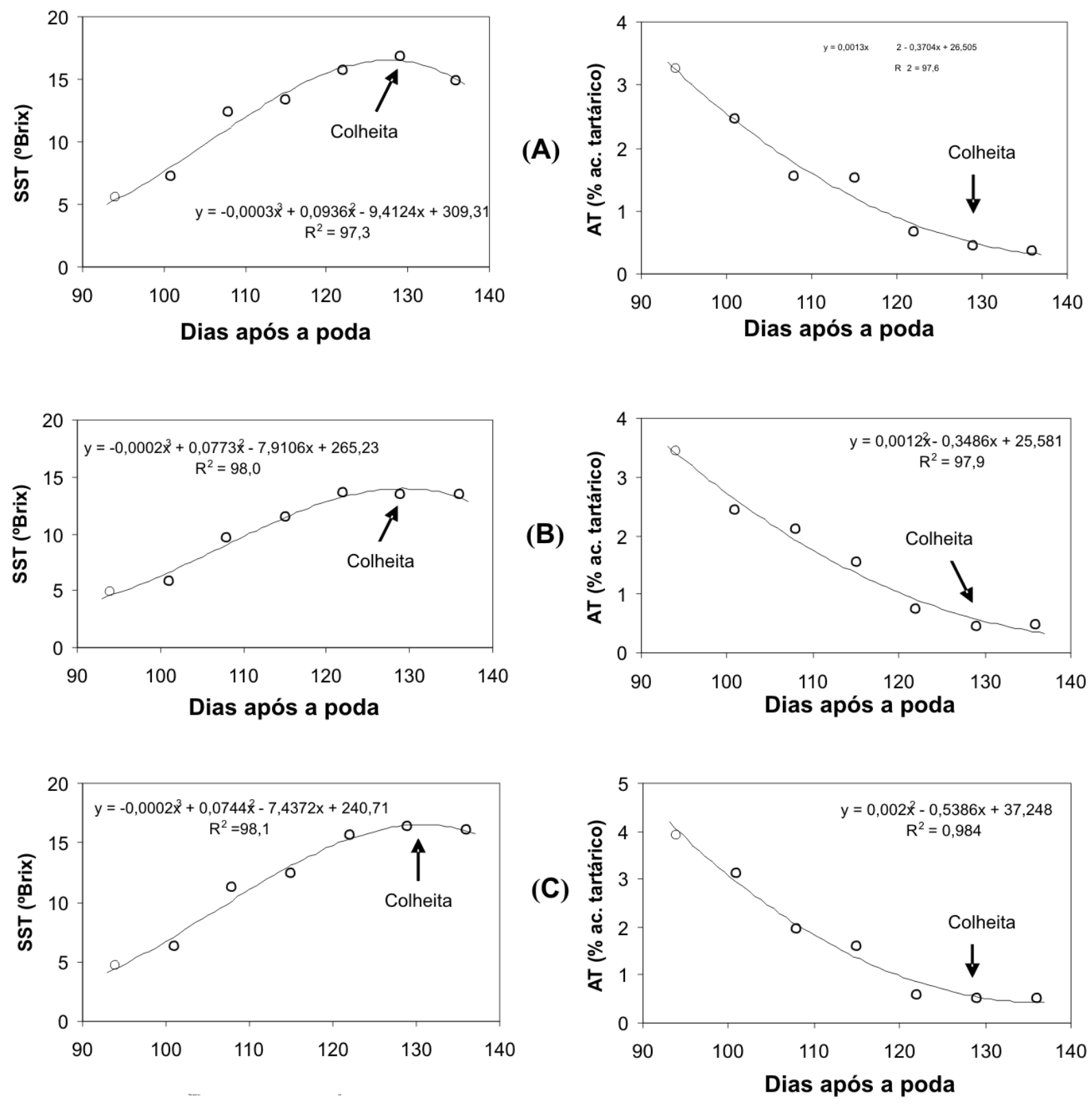

Figura 1. Evolução do teor de sólidos solúveis totais e da acidez titulável (\% de ácido tartárico) da 'Isabel' sobre os porta enxertos 'IAC 766 Campinas' (A), 'IAC 572 Jales' (B) e '420-A' (C) em Rolândia, PR. Obs: As setas indicam o momento da colheita. 
Por se tratar de uma relação de evolução inversa entre SST e AT o índice de maturação tende a apresentar semelhança em relação à evolução do teor de SST, ou seja, com baixos teores no início da maturação e aumento progressivo até o período próximo à colheita. Resultado semelhante foi encontrado por Manfroi et al. (2004) em estudo sobre a evolução da maturação da videira 'Cabernet Franc' na Serra Gaúcha, e por Rizzon, Miele e Meneguzzo (2000) em estudo sobre a evolução da maturação da 'Isabel' na Serra Gaúcha.

Em relação à evolução do $\mathrm{pH}$ do mosto das uvas (Figura 2), observa-se que indepedente do portaenxerto houve um crescimento progressivo em seu teor e todas as combinações melhor se ajustaram à regressão polinomial de terceiro grau ('IAC 766 Campinas': $\mathrm{R}^{2}=99,8$; 'IAC 572 Jales': $\mathrm{R}^{2}=99,1$; e ' $\left.420-A^{\prime}: R^{2}=96,9\right)$.

Verificou-se também que a evolução do $\mathrm{pH}$ apresentou comportamento inverso à evolução da acidez. Este resultado pode ser explicado pelo fato do aumento do $\mathrm{pH}$ nas bagas estar relacionado à salinificação dos ácidos orgânicos e ao aumento do cátion potássio (MANFROI et al., 2004).

Segundo Guerra, Daud e Rizzon (1992), o pH elevado dos mostos em regiões de climas quentes é conseqüência dos baixos teores dos ácidos tartárico e málico.

$\mathrm{O}$ pH influencia diretamente a estabilidade das antocianinas, portanto o conhecimento desta característica para cada combinação copa/portaenxerto é extremamente importante quando se deseja obter sucos com altos teores de matéria corante (MALACRIDA; MOTTA, 2006).

O conhecimento de um modelo de evolução das uvas é uma importante ferramenta para os viticultores conhecerem melhor as variedades com as quais desejam trabalhar e estimar o momento ideal para a sua colheita de acordo com a capacidade máxima de cada combinação, e desta forma ampliar as possibilidades de se obter uvas com a qualidade desejada para o processamento. Os resultados de evolução das características químicas da 'Isabel' obtidas neste trabalho, são semelhante aos resultados observados no Rio Grande do Sul, por Guerra, Daud e Rizzon (1992) e por Rizzon, Miele e Meneguzzo (2000). Apesar de serem necessários mais alguns anos de estudos, pode se considerar que esta uva apresenta características químicas durante a maturação compatíveis para a obtenção de matéria-prima com a finalidade de elaboração de suco, independentemente do porta-enxerto que se utiliza.

Em relação aos aspectos físicos das uvas, observase na Tabela 1, que para a massa e o comprimento dos cachos houve influência dos porta-enxertos sobre a 'Isabel', sendo que o 'IAC 766 Campinas' e o 'IAC 572 Jales' não diferenciaram entre si $(157,7$ e $155,0 \mathrm{~g} ; 12,5$ e $12,2 \mathrm{~cm}$, respectivamente) e foram superiores em relação ao 420-A (95,2 g e 10,7 cm, respectivamente).

Para a massa e o diâmetro das bagas não houve influência significativa dos porta-enxertos IAC 766 Campinas, IAC 572 Jales e 420-A sobre a copa, sendo que os resultados $(3,1 ; 3,25$ e $3,05 \mathrm{~g}$; 15,$2 ; 15,35$ e $14,2 \mathrm{~mm}$, respectivamente), obtidos foram semelhantes aos obtidos por Rizzon, Miele e Meneguzzo (2000) na Serra Gaúcha em sistema de latada (3 g e 15,7 mm, respectivamente).

Características como o número de cachos por planta, produção por planta e produtividade, foram influenciadas significativamente pelos portaenxertos. Destaca-se o 'IAC 766 Campinas' que apresentou os maiores valores $(84,5 ; 11,67 \mathrm{~kg}$ e 18,7 t), seguido do 'IAC 572 Jales' (74,2; 10,7 kg e 14,2 t) e do ' $420-\mathrm{A}$ ' (66,0; 4,7 $\mathrm{kg}$ e 7,65t). Esta diferença entre os porta-enxertos pode estar relacionado ao fato da tendência do 'IAC 766 Campinas' em imprimir um maior vigor à copa, e consequentemente fornecer melhores condições para se obter um número maior de cachos, enquanto que o '420-A' tende a limitar o vigor da copa, o que pode ter como consequência uma limitação na quantidade de cachos por planta. 

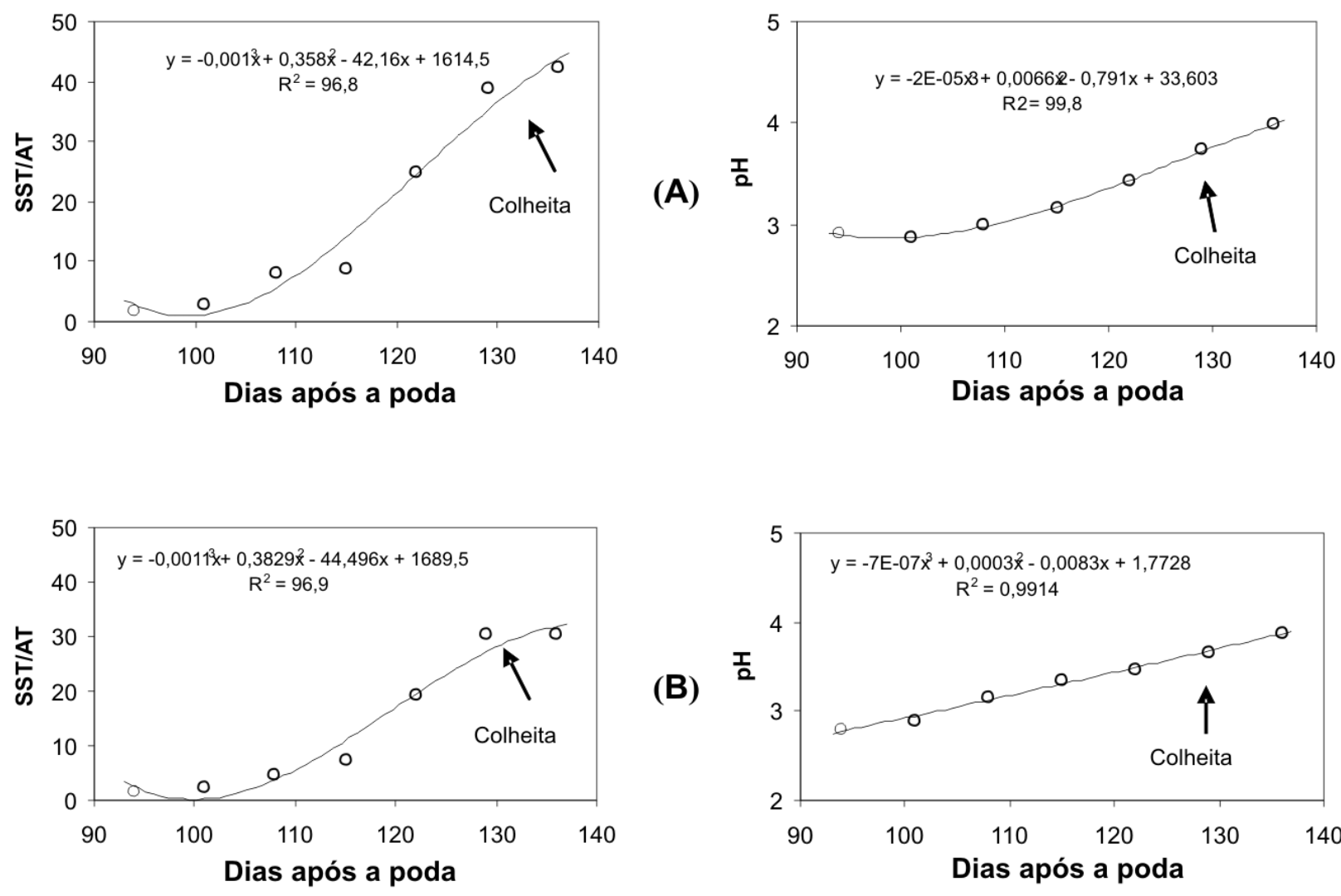

(B)
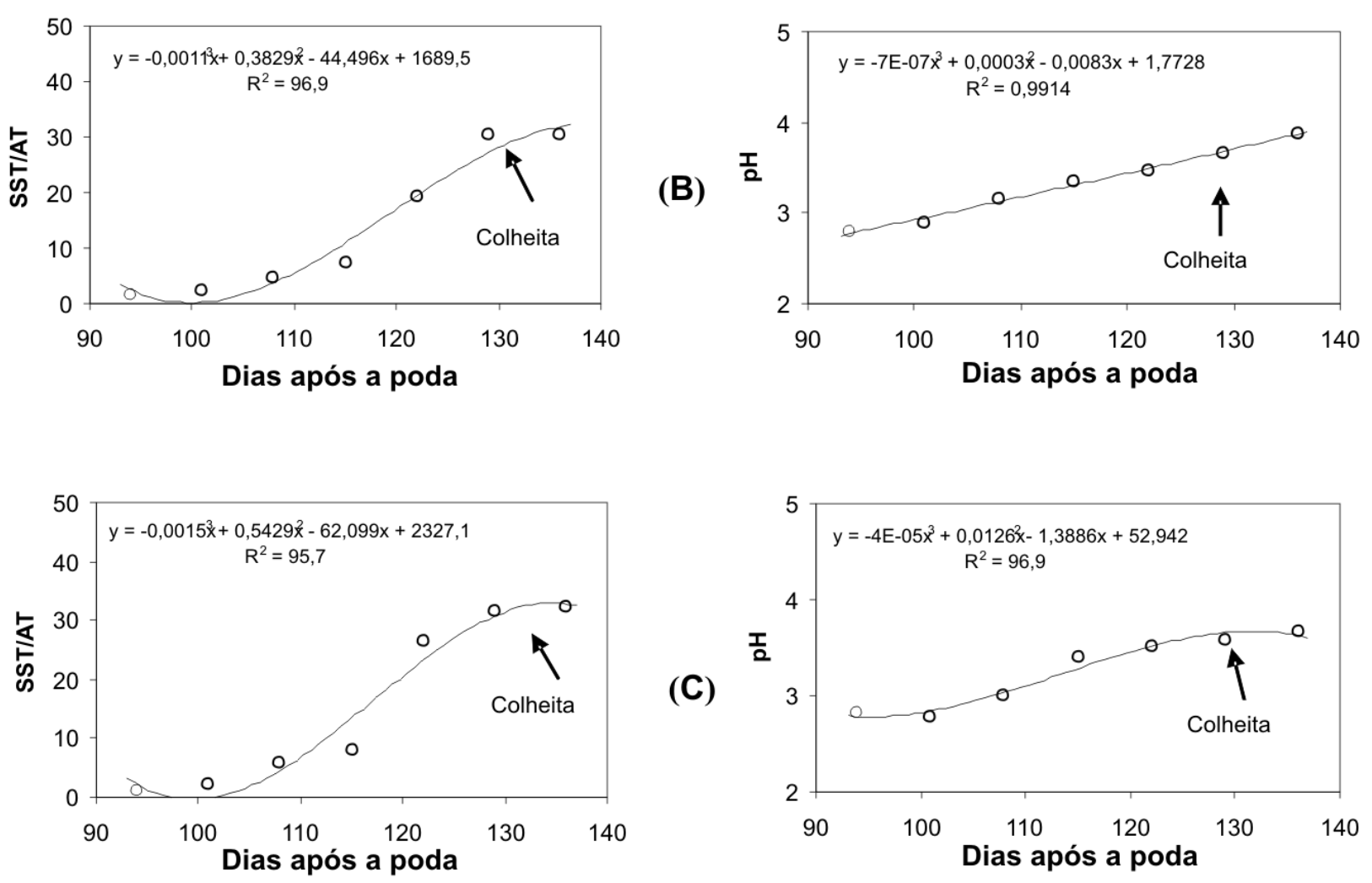

Figura 2. Evolução da relação SST/AT e pH da 'Isabel' sobre os porta enxertos 'IAC 766 Campinas' (A), 'IAC 572 Jales' (B) e '420-A' (C) em Rolândia, PR. Obs: As setas indicam o momento da colheita. 
Tabela 1. Características físicas e produtivas da uva 'Isabel' sobre diferentes porta-enxertos no momento da colheita. Londrina, PR, 2007.

\begin{tabular}{ccccc}
\hline & $\begin{array}{c}\text { 'IAC 766 } \\
\text { Campinas' }\end{array}$ & 'IAC 572 Jales' & '420-A' & CV(\%) \\
\hline Massa dos cachos & $157,7 \mathrm{a}$ & $155,0 \mathrm{a}$ & $94,2 \mathrm{~b}$ & 12,4 \\
Comprimento dos cachos & $12,5 \mathrm{a}$ & $12,2 \mathrm{a}$ & $10,7 \mathrm{~b}$ & 4,0 \\
Massa das bagas & $3,1 \mathrm{a}$ & $3,2 \mathrm{a}$ & $3,0 \mathrm{a}$ & 4,4 \\
Diâmetro das bagas & $15,2 \mathrm{a}$ & $15,3 \mathrm{a}$ & $14,2 \mathrm{a}$ & 4,9 \\
Número de cachos & $84,5 \mathrm{a}$ & $74,2 \mathrm{~b}$ & $66,0 \mathrm{c}$ & 10,3 \\
Produção & $11,7 \mathrm{a}$ & $10,7 \mathrm{~b}$ & $4,7 \mathrm{c}$ & 15,4 \\
Produtividade & $18,7 \mathrm{a}$ & $14,2 \mathrm{~b}$ & $7,6 \mathrm{c}$ & 14,4 \\
\hline
\end{tabular}

*Médias seguidas de mesma letras nas linhas não diferem entre si, pelo teste de Tukey a 5\%.

Embora o 'IAC 766 Campinas' tenha apresentado maior vigor em relação aos outros porta-enxertos, observa-se que quando comparados em outras regiões a quantidade de cachos por planta, produção e produtividade foram menores. Em Campina Verde, MG, Maia, Camargo e Nachtigal (2002) verificaram que a 'Isabel' apresenta em média 147,5 cachos por planta, ou seja 63 cachos acima do observado neste trabalho, no entanto, deve-se considerar que no experimento destes autores foi deixado um número superior de gemas ( 6 a 8 por vara).

Deve-se considerar também que nem sempre as grandes quantidades de cachos são interessantes quando se deseja uvas para elaboração de sucos, pois quanto maior o número de cachos, menor será a distribuição de carboidratos para os mesmos, o que pode prejudicar a qualidade da uva e consequentemente o seu suco (MORAES, 2003).

Além da quantidade de cachos por planta, observou-se que a produção e produtividade observados neste trabalho são inferiores quando comparados aos obtidos por Souza et al. (2002) no município de Caldas, MG em espaldeira, onde a produção foi de $14,6 \mathrm{~kg}$ por planta e a produtividade de 36,5 t/ha. Em Campina Verde, MG, Maia, Camargo e Nachtigal (2002) verificaram que a 'Isabel' conduzida em GDC apresentou média de $16,8 \mathrm{~kg}$ por planta e produtividade de $27,8 \mathrm{t} / \mathrm{ha}$. No entanto, deve-se levar em consideração que neste experimento a 'Isabel' encontra-se em seu segundo ano de produção, enquanto que em Caldas, $\mathrm{MG}$, as videiras encontravam-se em plena produção ( 3 a 7 anos de produção).

Estas diferenças podem estar relacionadas a diversos fatores, como densidade de plantas, condições climáticas, idade e vigor das plantas, sistema de condução, entre outros. Para este trabalho a densidade de plantas pode ter exercido influência significativa, pois o espaçamento entre linhas utilizado $(3,5 \mathrm{~m})$ poderia ser menor $(2,0 \mathrm{~m})$, o que poderia resultar em um incremento de $42 \%$ do número de plantas por área e consequentemente, uma maior produtividade.

Com relação aos aspectos químicos no momento da colheita (Tabela 2), observa-se que houve diferença significativa entre os porta-enxertos, sendo que o 'IAC 766 Campinas' e o 'IAC 572 Jales' não difereciaram entre si e apresentaram as maiores médias ( 16,8 e $\left.16,3^{\circ} \mathrm{Brix}\right)$, enquanto que o '420-A' apresentou menor média (13,4 $\left.{ }^{\circ} \mathrm{Brix}\right)$. A diferença entre os porta-enxertos, assim como para as características físicas, pode ser explicado devido ao maior vigor que o 'IAC 766 Campinas' e o 'IAC 572 Jales' imprimem à copa, o que fornece uma maior capacidade de acúmulo de carboidratos pelas bagas. 
Tabela 2. Características químicas da uva 'Isabel' sobre diferentes porta-enxertos, no momento da colheita. Londrina, PR, 2007.

\begin{tabular}{ccccc}
\hline & 'IAC 766 Campinas' & 'IAC 572 Jales' & '420-A' & CV(\%) \\
\hline Sólidos Solúveis Totais (SST) & $16,8 \mathrm{a}$ & $16,3 \mathrm{a}$ & $13,4 \mathrm{~b}$ & 6,0 \\
Acidez titulável (AT) & $0,5 \mathrm{a}$ & $0,5 \mathrm{a}$ & $0,5 \mathrm{a}$ & 14,4 \\
Relação SST/AT & $38,8 \mathrm{a}$ & $30,2 \mathrm{a}$ & $31,5 \mathrm{a}$ & 19,2 \\
pH & $3,7 \mathrm{a}$ & $3,7 \mathrm{a}$ & $3,6 \mathrm{a}$ & 6,6 \\
\hline
\end{tabular}

* Médias seguidas de mesma letra nas linhas não diferem entre si, pelo teste de Tukey a 5\%.

Os teores de SST observados durante a colheita são superiores aos obtidos por Maia et al. (2006) em Rolândia, PR e por Souza et al. (2002) em Caldas, MG (15,7 e 15,0 respectivamente).

Em relação ao teor de AT, índice de maturação e $\mathrm{pH}$, não houve diferença significativa entre os porta-enxertos e verificou-se que os valores de acidez obtidos $(0,45 ; 0,45$ e $0,50 \%$ para 'IAC 766 Campinas', 'IAC 572 Jales' e '420-A', respectivamente) estão dentro do ideal para uvas destinadas à produção de sucos $(0,4$ e $0,6 \%)$ (RIZZON; MENEGUZZO; MANFROI, 2004). $\mathrm{O}$ índice de maturação $(38,8 ; 30,2$ e 31,5 para 'IAC 766 Campinas', 'IAC 572 Jales' e '420-A', respectivamente) também encontram-se dentro do exigido pela legislação brasileira (entre 15 e 45). Para o $\mathrm{pH}$ observou-se valores um pouco acima do esperado $(3,7 ; 3,7$ e 3,6) , pois segundo Rizzon, Meneguzzo e Manfroi (2004), para a obtenção de um suco de uva de qualidade, o pH do mosto ideal deve estar entre 3,1 e 3,3.

As características fisico-químicas observadas para a 'Isabel' neste trabalho, embora preliminares, permitem considerar que esta uva no Norte do Paraná apresenta condições ideais para elaboração de sucos, sendo o porta enxerto 'IAC 766 Campinas' o mais indicado para a enxertia desta uva.

\section{Conclusões}

Os porta-enxertos exerceram influência semelhante para a evolução de maturação e as curvas de maturação melhor se ajustaram às regressões de terceiro grau para SST, SST/AT e pH e segundo grau para a AT.

Para as características físicas dos cachos houve influência do porta-enxerto somente para a sua massa e comprimento.

As características produtivas como produção/ planta e produtividade, são influenciadas pelo portaenxerto, sendo o 'IAC 766 Campinas' superior em relação aos demais.

Para as características químicas das bagas no momento da colheita houve influência do portaenxerto somente para o teor de SST, sendo as maiores médias obtidas pelo 'IAC 766 Campinas' e o 'IAC 572 Jales'.

\section{Referências}

BLOUIN, J.; GUIMBERTEAU, G. Maduración y madurez de la uva. Madrid: Mundi-Prensa, 2004.

CAMARGO, U. A. Espécies e cultivares. In: EMPRESA BRASILEIRA DE PESQUISA AGROPECUÁRIA - EMBRAPA/CNPUV. Uva para processamento e produção. Brasília: Embrapa Informação Tecnológica, 2003. p. 34-44. 
CAMARGO, U. A. Suco de uva: matéria-prima para produtos de qualidade e competitividade. In: CONGRESSO LATINO-AMERICANO DE VITICULTURA E ENOLOGIA, 10., 2005, Bento Gonçalves. Anais... Bento Gonçalves: Embrapa Uva e vinho, 2005. p. 195.

GUERRA, C. C.; DAUD, C. E.; RIZZON, L. A. Evolução dos teores de ácidos tartárico e málico durante a maturação de uvas tintas. Pesquisa Agropecuária Brasileira, Brasília, v. 27, n. 3, p. 473-478, 1992.

INSTITUTO ADOLFO LUTZ. Normas analíticas do Instituto Adolfo Lutz: métodos químicos e físicos para análise dos alimentos. 3.ed. São Paulo: Instituto Adolfo Lutz, 1985. v. 1.

KISHINO, A. Y.; GENTA, W.; ROBERTO, S. R. Produção de uvas no Paraná. In: KISHINO, A. Y.; CARVALHO, S. L. C.; ROBERTO, S. R. Viticultura tropical. Londrina: IAPAR, 2007. p. 20-22.

MAIA, J. D. G.; CAMARGO, U. A.; GASPARIN, M. D.; KIKUDA, R. W. Avaliação de cultivares de uvas para suco em Rolândia, Região Norte do Paraná. In: CONGRESSO BRASILEIRO DE FRUTICULTURA, 19., 2006, Cabo Frio. Anais... Cabo Frio: SBF, 2006. p. 235.

MAIA, J. D. G.; CAMARGO, U. A.; NACHTIGAL, J. C. Avaliação da cv. Isabel em três sistemas de condução e em dois porta-enxertos para a produção de suco em região tropical. In: CONGRESSO BRASILEIRO DE FRUTICULTURA, 17., 2002, Belém. Anais... Belém: SBF, 2002. CDROM.

MALACRIDA, C. R.; MOTTA, S. Antocianina em suco de uva: composição e estabilidade. Boletim do CEPPA, Curitiba, v. 24, n. 1, p. 59-82, 2006.
MANFROI, L.; MIELE, L.; RIZZON, L. A.; BARRADAS, C. I. N.; SOUZA, P. V. D. Evolução da maturação da uva Cabernet Franc conduzida no sistema lira aberta. Ciência Agrotecnica, Lavras, v. 28, n. 2, p. 306-313, 2004.

MELLO, L. M. R. Panorama. In: ANUÁRIO Brasileiro da Uva e do Vinho, Santa Cruz do Sul, 2006. p. 63-63.

MORAES, A. L. Produção da 'Niagara Rosada' em função da desfolha após colheita. 2003. Tese. (Mestrado em Agronomia) - Escola Superior de Agricultura Luiz de Queiroz da Universidade de São Paulo, Piracicaba.

POMMER, C. V.; MAIA, M. L. Introdução. In: POMMER, C. V. Uva: tecnologia de produção, póscolheita, mercado. Porto Alegre: Cinco Continentes, 2003. p. 11-36.

RIZZON, L. A.; MANFROI, V.; MENEGUZZO, J. Elaboração de suco na propriedade vitícola. Bento Gonçalves: Embrapa Uva e Vinho, 1998.

RIZZON, L. A.; MENEGUZZO, J.; MANFROI, L. Processamento de uva, vinho tinto, graspa e vinagre. Brasília: Embrapa Informação Tecnológica, 2004.

RIZZON, L. A.; MIELE, A.; MENEGUZZO, J. Avaliação da uva cv. Isabel para elaboração de vinho tinto. Ciência Tecnologia de Alimentos, Campinas, v. 20, n. 1, p. 115121, 2000.

SOUZA, C. M.; REGINA, M. A.; PEREIRA, G. E.; FREITAS, G. F. Indicação de cultivares de videira para o sul de Minas Gerais. Viticultura e enologia: atualizando conceitos. Caldas Novas: Epamig, 2002. p. 277-286. 